\title{
Correction to: Gendered behavior as a disadvantage in open source software development
}

Balazs Vedres ${ }^{1,2^{*}}$ and Orsolya Vasarhelyi ${ }^{2}$

\section{"Correspondence:}

balazs.vedres@oii.ox.ac.uk

'Oxford Internet Institute, University of Oxford, Oxford, United Kingdom ${ }^{2}$ Department of Network and Data Science, Central European

University, Budapest, Hungary
Following publication of the original article [1], we have been notified that one more affiliation of the corresponding author is missing.

Currently Balasz Vedres affiliation is:

1 Oxford Internet Institute, University of Oxford, Oxford, United Kingdom It should be:

1 Oxford Internet Institute, University of Oxford, Oxford, United Kingdom;

2 Department of Network and Data Science, Central European University, Budapest, Hungary.

\section{Publisher's Note}

Springer Nature remains neutral with regard to jurisdictional claims in published maps and institutional affiliations.

Published online: 19 September 2019

\section{References}

1. Vedres B, Vasarhelyi O (2019) Gendered behavior as a disadvantage in open source software development. EPJ Data Sci 8:25. https://doi.org/10.1140/epjds/s13688-019-0202-z 